\title{
Association of Insulin Receptor Substrate-1 Gene Polymorphism (rs1801278) with Alzheimer's Disease
}

\author{
Parham Niyasti $^{\mathrm{a}, 1}$, Alia Saberi ${ }^{\mathrm{b}, 1}$, Hamidreza Hatamyain ${ }^{\mathrm{b}}$, Farzam Ajamian ${ }^{\mathrm{c}}$, \\ Samaneh Ghorbani Shirkouhi ${ }^{\mathrm{d}, \mathrm{e}}$, Laleh Mirzanejad ${ }^{\mathrm{c}}$ and Sasan Andalib ${ }^{\mathrm{f}, \mathrm{g}, \mathrm{h}, *}$ \\ ${ }^{a}$ School of Medicine, Guilan University of Medical Sciences, Rasht, Iran \\ ${ }^{\mathrm{b}}$ Neuroscience Research Center, Department of Neurology, Poursina Hospital, School of Medicine, Guilan \\ University of Medical Sciences, Rasht, Iran \\ ${ }^{\mathrm{c}}$ Department of Biology, Faculty of Sciences, University of Guilan, Rasht, Iran \\ ${ }^{\mathrm{d}}$ School of Medicine, Shahroud University of Medical Sciences, Shahroud, Iran \\ ${ }^{\mathrm{e}}$ Neuroscience Research Center, Poursina Hospital, Guilan University of Medical Sciences, Rasht, Iran \\ ${ }^{\mathrm{f}}$ Department of Clinical Research, University of Southern Denmark, Odense, Denmark \\ ${ }^{\mathrm{g}}$ Research Unit of Clinical Physiology and Nuclear Medicine, Department of Nuclear Medicine, \\ Odense University Hospital, Odense, Denmark \\ ${ }^{\mathrm{h}}$ Neuroscience Research Center, Poursina Hospital, School of Medicine, Guilan University of Medical Sciences, \\ Rasht, Iran
}

Received 14 November 2021

Accepted 25 January 2022

Pre-press 9 February 2022

Published 23 February 2022

\begin{abstract}
.
Background: Alzheimer's disease (AD) is the most common form of dementia. $\mathrm{AD}$ is also the leading cause of morbidity and mortality due to dementia worldwide. It has been shown that AD is associated with type 2 diabetes mellitus (T2DM) and brain insulin resistance. Rs 1801278 is a polymorphism in insulin receptor substrate-1 (IRS-1) gene which changes the amino acid Arg972. This polymorphism has been found to be associated with susceptibility to AD in some populations.

Objective: In the present study, our aim was to investigate the association of Arg972 IRS-1 (rs1801278) gene polymorphism and late-onset Alzheimer's disease (LOAD) in an Iranian population.

Methods: In this case-control study, 150 patients with LOAD and 150 unrelated healthy controls were recruited. Polymerase chain reaction (PCR) was performed to amplify a DNA segment of 263 base-pair (bp) length containing the single nucleotide polymorphism (SNP). The PCR product was then incubated with Mval restriction enzyme to undergo enzymatic cleavage. Electrophoresis was thereafter carried out using agarose gel and DNA safe stain. The gel was ultimately visualized under a UV trans-illuminator. Allelic and genotypic frequencies were then compared.

Results: A allele (mutant) of the gene was significantly associated with the risk of AD after adjustment for sex and age $(p=0.04$, adjusted OR:1.77, 95\% CI:1.00-3.11). Only AA genotype (mutant homozygote) was significantly associated with the risk of AD after adjustment for sex and age ( $p=0.01$, adjusted OR:2.39, 95\% CI:1.22-4.66).
\end{abstract}

\footnotetext{
${ }^{1}$ These authors contributed equally to this work.

* Correspondence to: Sasan Andalib, Department of Clinical Research, University of Southern Denmark, Odense, Denmark. E-mail: andalib@health.sdu.dk.
} 
Conclusion: SNP rs1801278 is significantly associated with the risk of developing AD in the studied Iranian population.

Keywords: Alzheimer's disease, insulin receptor substrate-1, polymorphism, rs 1801278

\section{INTRODUCTION}

Alzheimer's disease (AD) is the most common form of dementia and also the leading cause of morbidity and mortality due to dementia worldwide [1]. $\mathrm{AD}$ is characterized by neuronal cell death [2] which arises from extracellular amyloid- $\beta(A \beta)$ plaques and intracellular tau neurofibrillary tangles (NFTs) [3]. The World Alzheimer Report indicated about 47 million $\mathrm{AD}$ or $\mathrm{AD}$-related dementia throughout the world in 2015 [4]. It is anticipated that, as the world's population is aging, the number of patients with dementia, will grow to 130 million worldwide in 2050 [1, 4]. $\mathrm{AD}$ is classified into two forms of familial early-onset $\mathrm{AD}$ and sporadic late-onset AD (LOAD), constituting 3\% and $97 \%$ of the AD cases, respectively [5]. The progression of LOAD occurs normally after 65 years of age [6].

It is believed that $\mathrm{AD}$ is associated with some gene mutations. Mutations of $A \beta$ precursor protein and presenilin 1 and 2 in familial AD or LOAD and mutations of $\varepsilon 4$ allele of $A P O E$ ( $A P O E \varepsilon 4)$ gene in sporadic cases of $\mathrm{AD}$ have been reported [7, 8]. $\mathrm{AD}$ is also associated with polymorphisms of TREM2 [9], MS4A6A [10], and CD33 genes [11].

Epidemiological and experimental studies suggest that insulin resistance is a key risk factor for type 2 diabetes mellitus (T2DM), AD, and other ADrelated dementias [12]. An epidemiological study showed that T2DM is associated with an increased risk of $\mathrm{AD}$ [3]. The incidence of dementia increases by $50-100 \%$ relative to people without diabetes [13]. In Iran, prevalence of impaired fasting glucose and total DM were $14.60 \%$ (95\% CI: 12.41-16.78) and $11.37 \%$ (95\% CI: 9.86-12.89) among individuals with 25-70 years of age, respectively, in 2011 [14]. The number of DM patients is estimated to rise to 9.24 million cases by 2030 in Iran [15]. In a cohort study carried out in Guilan province of Iran (2014-2017), prevalence of DM was $24.1 \%$ [16].

Recently, it has been shown that the central nervous system (CNS) insulin resistance can be present apart from peripheral insulin resistance of T2DM in individuals with LOAD [17-20].

Neuronal growth, development, and neurogenesis have important roles in insulin function in the CNS $[18,19]$. The role of insulin in neuronal cells is mediated by two main signaling pathways, that is to say, insulin - insulin receptor substrate (IRS) - protein kinase B (AKT) pathway and mitogen-activated protein kinase pathway [20]. Insulin - IRS1 - PI3K (phosphoinositide 3-kinase) - AKT - TBC1D4 signaling induces cognition and emotional function in hippocampus. In addition, insulin - IRS1 - PI3K AKT - GSK3 $\beta$ (glycogen synthase kinase 3 ) has a role in neuroplasticity and neurogenesis [20].

In animal models, brain insulin level alterations can influence neuronal glucose uptake and metabolism due to glucose transporter type 4 (GLUT4) translocation arising from insulin - IRS1 - AKT signaling pathway in the basal forebrain, hippocampus, amygdala, and to a lesser degree, in the cerebral cortex and cerebellum [21-24]. Under the condition of highenergy demand during spontaneous alternation tests of spatial working memory, this mechanism can promote cognitive activity in the hippocampus in rats [21-23].

Brain insulin resistance can result from insulinlike growth factor-1 (IGF-1) resistance and IRS-1, 2 malfunctions induced by $A \beta$ accumulation [25]. There is a two-sided relationship between brain insulin resistance and $A \beta$ plaque deposition in the brain [26].

Arg972 IRS-1 gene polymorphism (rs1801278) results in a Gly/Arg substitution at codon 972 (Arg972) that impairs IRS-1 ability to activate the downstream PI3K signaling pathway. Therefore, it can lead to insulin signaling malfunction [6]. Lack of insulin signaling is proposed to upregulate amyloidogenic and Tau NFT-genic pathways. There is a higher prevalence of this polymorphism in T2DM [27] and AD patients [28].

Albegali et al. [29] and Alharbi et al. [30] have found significant association of rs 1801278 variant with T2DM ( $p<0.001$ and $p=0.04$, respectively). $\mathrm{Li}$ et al. [31] in a meta-analysis, found significant association between rs1801278 and T2DM risk in recessive model (AA versus $\mathrm{GA}+\mathrm{GG}, p=0.043$ ) and codominant model (AA versus GG, $p=0.007$ ).

In contrast, some studies have shown no association of IRS- 1 gene polymorphisms with $\mathrm{AD}$ in Caucasian populations [27, 32-35], but a Chinese study evaluating the association of rs 1801278 polymorphism with $\mathrm{AD}$ in a Han Chinese population 
revealed a significant association of the polymorphism and AD [28].

An explanation for this discrepancy could be the possible effects of ethnic populations on the mentioned association [28].

As little is known about the association of Arg972 IRS-1 (rs1801278) with AD in the Iranian ethnic population, we set out the present study to test the hypothesis of the presence of the association between the polymorphism and AD in an Iranian population in the north of Iran.

\section{MATERIALS AND METHODS}

\section{Subjects}

Given the results of previous published research [28] and considering type 1 error $(\alpha)=0.05$, type 2 error $(\beta)=0.1$ (power of study $=90 \%$ ), and a casecontrol ratio of one-to-one, a minimum sample size of 148 participants in each group was calculated and considered as a prerequirement for this study. Therefore, 150 patients with LOAD and 150 unrelated healthy subjects were enrolled in Guilan province in the north of Iran. Inclusion criteria included patients with probable LOAD diagnosed according to the National Institute on Aging and Alzheimer's Association (NIA-AA) diagnostic criteria of AD [36]. Exclusion criteria for the patients were the history of head trauma, stroke, motor neuron disease, congenital dementia, neurological infections, neuropsychologic systemic lupus erythematosus, sarcoidosis, multiple sclerosis, other neurodegenerative diseases, and familial history of AD in first-class relatives. Informed consent was obtained from all the participants. This study was approved by the ethics committee of Guilan University of Medical Sciences.

\section{Genotyping}

Five milliliters of peripheral blood sample were collected from the participants and stored in TrisEDTA $5 \%$ buffer at $-30^{\circ} \mathrm{C}$. DNA was extracted by a salting-out method from white blood cells. Forward and reverse primers were synthesized and used for PCR amplification. Restriction enzyme MvaI was used for Restriction Fragment Length Polymorphism (RFLP) as previously described [37].

PCR amplification was performed for all samples using respective forward and reverse primers. In the next step, PCR products were incubated and digested by MvaI. PCR-RFLP characteristics are shown in Table 1.

Table 1

Enzymatic digestion reaction characteristics

\begin{tabular}{cl}
\hline Forward primer & $5^{\prime}$ - CTT CTG TCA GGT GTC CAT CC-3' \\
Reverse primer & $5^{\prime}$ - TGG CGA GGT GTC CAC GTA GC-3' \\
Restriction enzyme & MvaI \\
Recognition & $5^{\prime} \ldots$ C C $\downarrow W ~ G ~ G \ldots 3^{\prime}$ \\
sequence & $3^{\prime} \ldots$ G G W $\uparrow$ C C ... 5' \\
Restriction & GG genotype: $263 \mathrm{bp}$ \\
fragments & GA genotype: 263,180 , and $83 \mathrm{bp}$ \\
& AA genotype: 180 and $83 \mathrm{bp}$ \\
\hline
\end{tabular}

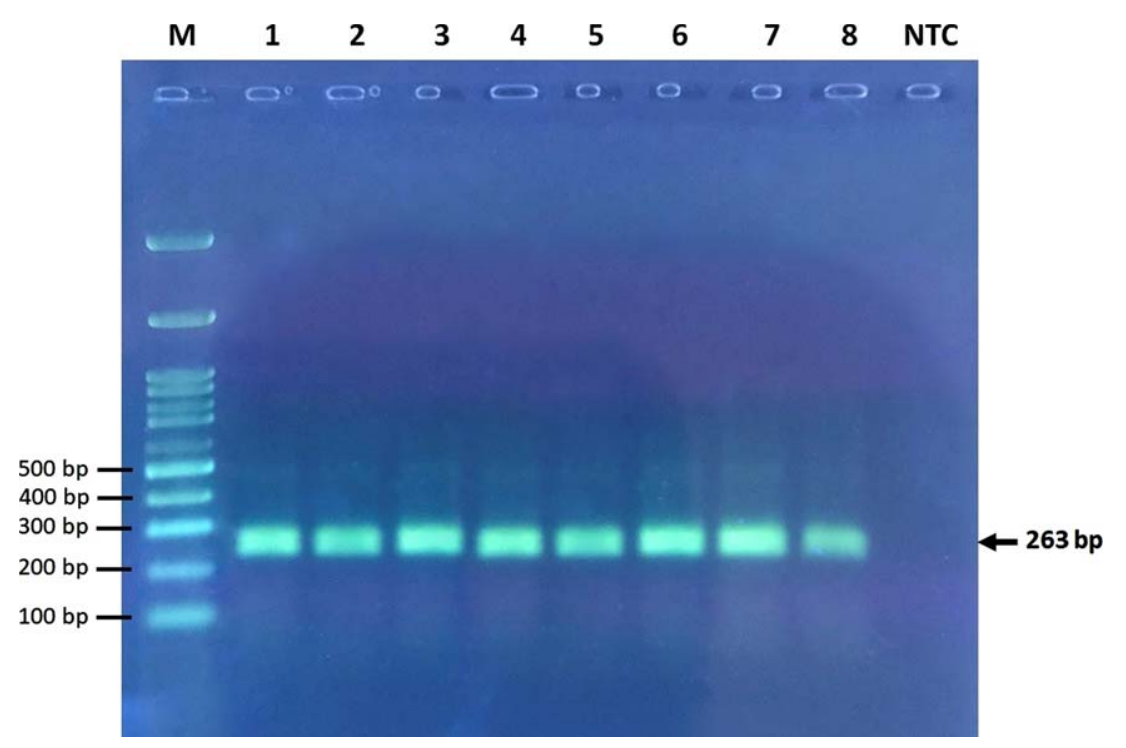

Fig. 1. Electrophoresis of undigested PCR products. M, marker ladder; NTC, no template control ladder. 


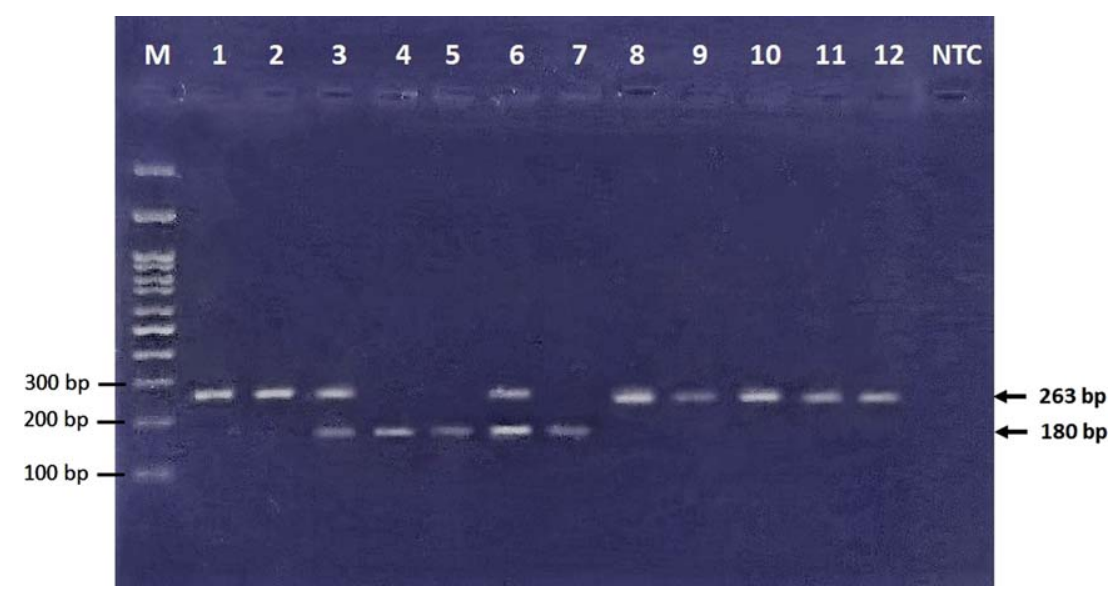

Fig. 2. Electrophoresis of restriction products. 83 bp band cannot be visualized in this figure due to usage of $3 \%$ agarose gel, which can show DNA fragment size of larger than $100 \mathrm{bp}$. GG (wild type homozygote genotype) $\longrightarrow$ Bands No. 1, 2, 8-12 (263 bp). GA (heterozygote genotype) $\longrightarrow$ Bands No. 3, 6 (263, 180, and 83 bp). AA (mutant homozygote genotype) $\longrightarrow$ Bands No. 4, 5, 7 (180 and 83 bp).

Electrophoresis was carried out using $3 \%$ agarose gel and visualized by DNA-safe stain using a UV trans-illuminator (Figs. 1 and 2). A few samples were sequenced to illustrate wild-type and variant allele sequences.

\section{Statistical analysis}

Hardy-Weinberg equilibrium analysis was performed with chi-square goodness-of-fit test. Categorical variables were expressed as $\mathrm{n}(\%)$ and analyzed with chi-square test or Fisher's exact test where appropriate. Continuous variables were expressed as mean \pm standard deviation (SD) and analyzed with independent samples $T$-test. Comparison of genotype and allele frequencies between patients and controls were made using the logistic regression analysis to assess odds ratio (OR) and 95\% confidence interval (CI). Statistical analyses were performed using SPSS (version 26). $\alpha=0.05$ was used as statistical level of significance.

\section{RESULTS}

Data from 300 subjects in two groups of cases and controls were collected and analyzed. The mean \pm SD of age in the case and control groups was $83.01 \pm 7.24$ and $76.94 \pm 9.54$, respectively $(p<0.001)$. Thirty-eight $(25.3 \%)$ and sixty-two $(41.3 \%)$ were male in the case and control groups, respectively $(p=0.002)$.

The genotype frequencies of the IRS- 1 gene rs1801278 polymorphism were not in Hardy-Weinberg equilibrium in both groups.
Figure 3 displays sequencing results of the wildtype and variant alleles of the Arg972 IRS-1 gene polymorphism (rs1801278).

The prevalence of A (mutant) allele in case and control groups were $31.67 \%$ and $19.67 \%$, respectively. By using logistic regression analysis and considering age, sex, and allelic frequencies as covariates, A allele was significantly associated with the risk of $\mathrm{AD}$ after adjustment for sex and age ( $p=0.04$, adjusted OR: 1.77, 95\% CI: 1.00-3.11) (Table 2).

The prevalence of AA (mutant homozygote IRS- 1 polymorphism) genotype in case and control groups were $26 \%$ and $11.33 \%$, respectively (Table 2 ). The prevalence of GA (heterozygote IRS- 1 polymorphism) genotype in the case and the control groups were $11.33 \%$ and $16.67 \%$, respectively. By using logistic regression analysis and considering age, sex, and genotypic frequencies as covariates, only AA genotype was significantly associated with the risk of $\mathrm{AD}$ after adjustment for sex and age $(p=0.01$, adjusted OR: $2.39,95 \%$ CI: 1.22-4.66). GA genotype was not associated with the risk of $\mathrm{AD}$ after adjustment for sex and age ( $p=0.37$, adjusted OR: $0.71,95 \%$ CI: $0.34-1.48$ ).

\section{DISCUSSION}

In this case-control study, we enrolled 150 LOAD patients and 150 unrelated controls for evaluation of the association of Arg972 IRS-1 gene polymorphism with the risk of $\mathrm{AD}$ in an Iranian population. A allele was significantly associated with the risk of $\mathrm{AD}$, compared to $G$ allele after adjustment for sex and age. 

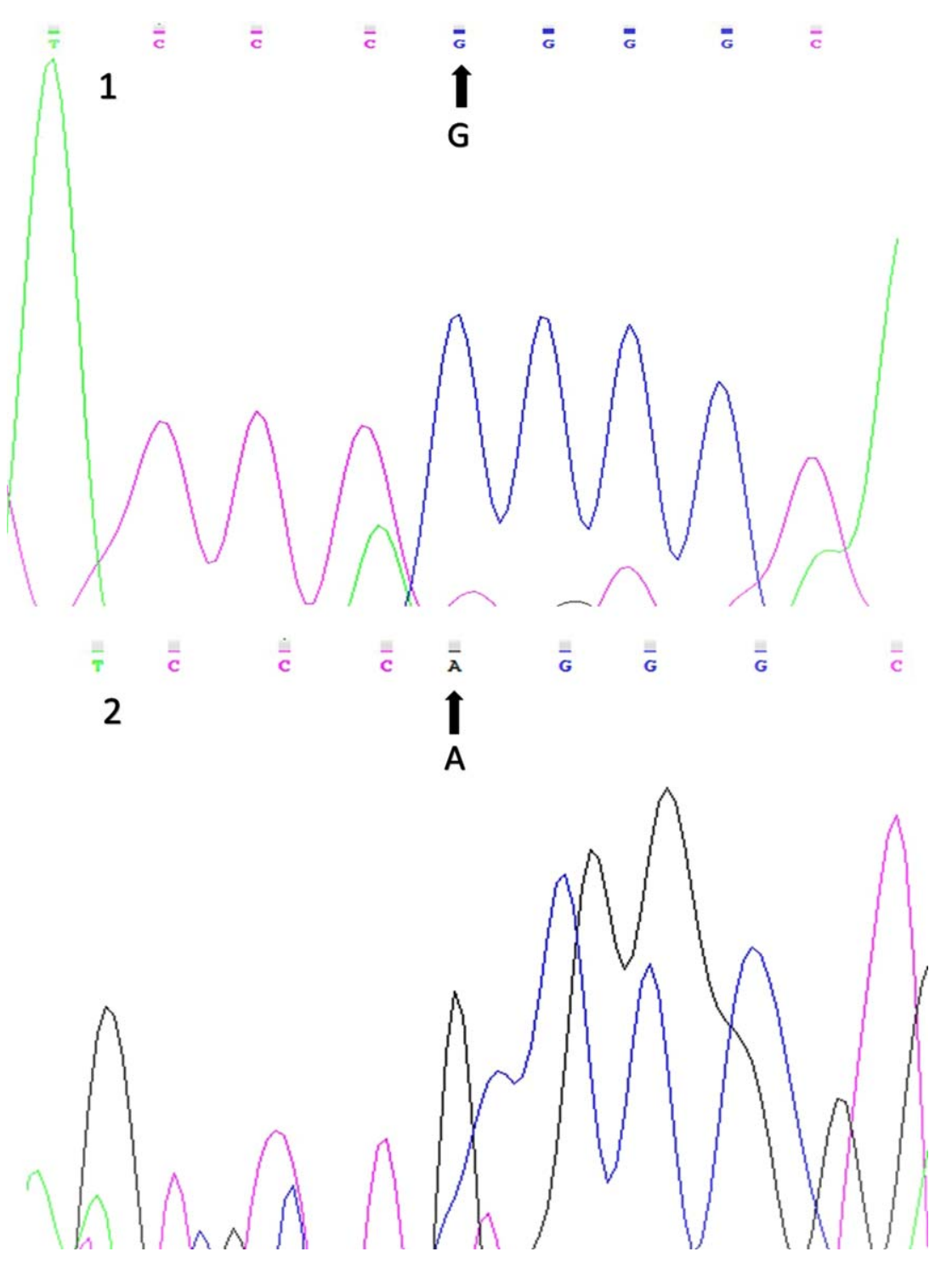

Fig. 3. Sequencing results for the Arg972 IRS-1 (rs1801278) gene polymorphism (1: wild-type allele; 2: variant allele).

Furthermore, AA genotype was significantly associated with the risk of $\mathrm{AD}$, in contrast to $\mathrm{GG}$ and $\mathrm{GA}$ genotypes after adjustment for sex and age.

To the best of our knowledge, only one study evaluated the association of Arg972 IRS-1 (rs1801278) gene polymorphism with the risk of AD [28]. Wang et al. [28] in a case-control study in 2014, evaluated 1113 AD patients and 1113 healthy controls which were matched for sex, age, body mass index, residence area, and education level. The authors showed that $5.7 \%$ of the patients and $2 \%$ of the controls had AA genotype (mutant homozygote), respectively and $42.3 \%$ of the patients and $20.1 \%$ of the controls had GA genotype (heterozygote Arg972
IRS-1), respectively. Moreover, the authors found that both genotypes were significantly associated with an increased risk of $\mathrm{AD}$ after adjustment for comorbidities including T2DM, coronary artery disease, and hypertension $(p<0.001)$ [28]. Also, 26.8\% of the patients and $12 \%$ of the controls carried the mutant $\mathrm{A}$ allele, respectively and the A allele was significantly associated with an increased risk of $\mathrm{AD}$ after adjustment for the above-mentioned comorbidities $(p<0.001)$. On the other hand, in each age sub-group of the cases, the prevalence of AA genotype, unlike GG genotype, in patients with a Mini-Mental State Examination (MMSE) score $\leq 14$ was high, compared with that in patients 
Table 2

Comparison of genotypic and allelic frequencies of Arg972 IRS1 gene polymorphism between $\mathrm{AD}$ cases $(N=150)$ and healthy controls $(N=150)$

\begin{tabular}{lcccc}
\hline $\begin{array}{l}\text { Genotype \& } \\
\text { Allele }\end{array}$ & $\begin{array}{c}\text { Cases } \\
N(\%)\end{array}$ & $\begin{array}{c}\text { Controls } \\
N(\%)\end{array}$ & $\begin{array}{c}\text { Adjusted OR } \\
(95 \% \mathrm{CI})\end{array}$ & $p$ \\
\hline GG & $94(\% 62.67)$ & $108(\% 72)$ & $\begin{array}{c}1.00^{\mathrm{a}} \\
(\text { Reference })\end{array}$ & - \\
GA & $17(\% 11.33)$ & $25(\% 16.67)$ & $\begin{array}{c}0.71^{\mathrm{a}} \\
(0.34-1.48)\end{array}$ & 0.37 \\
& & & $\begin{array}{c}2.39^{\mathrm{a}} \\
\text { AA }\end{array}$ & 0.01 \\
G & $39(\% 26)$ & $17(\% 11.33)$ & $\begin{array}{c}(1.22-4.66) \\
1.00^{\mathrm{b}}\end{array}$ & - \\
& $205(\% 68.3)$ & $241(\% 80.3)$ & $\begin{array}{c}\text { (Reference) } \\
1.77^{\mathrm{b}}\end{array}$ & 0.04 \\
A & $95(\% 31.67)$ & $59(\% 19.67)$ & $(1.00-3.11)$ & \\
\hline
\end{tabular}

${ }^{a}$ Adjusted OR is based on the logistic regression with covariates to be age, sex, and genotypic frequency. ${ }^{\mathrm{b}}$ Adjusted OR is based on the logistic regression with covariates to be age, sex, and allelic frequency.

with MMSE score $\geq 15-26(p<0.001)$. Furthermore, it was demonstrated that patients with GG genotype had higher MMSE score in each age group, compared with GA and AA genotypes $(p<0.05)$. It was concluded that Arg972 IRS-1 (rs1801278) gene polymorphism is significantly associated with $\mathrm{AD}$ in Han Chinese population. Moreover, the authors stated that this polymorphism may also have a prognostic value for $\mathrm{AD}[28]$.

The findings of the study of Wang et al. [28], were in agreement with those of our study demonstrating a significant association of A allele and AA genotype with increased risk of AD. Unlike the findings of Wang et al. [28], we did not find a higher prevalence of GA genotype in the patients even after adjustment for sex and age.

Hamilton et al. [33] investigated the role of insulin signaling-related candidate gene polymorphisms in 954 LOAD patients higher than 60 years of age and 1,106 controls in a Caucasian population in England. The authors showed that there was no significant association of $I R S-1$ polymorphism (rs1801123) with AD.

Giedraitis et al. [32] used available data from two genome-wide association studies $[34,35]$. They showed that $I R S-1$ polymorphism (rs10187726) had a significant association with LOAD in one of the mentioned studies [34].

In addition, the literature suggests no association of other IRS-1 gene variants (rs2234931, rs2943634) with AD in Caucasian populations [28, 32, 33, 35, $38,39]$.
The above-mentioned studies suggest possible ethnic influences on the association between IRS- 1 gene variants and the risk of $\mathrm{AD}$.

There are caveats with respect to the present study. First, data concerning comorbidities and clinical characteristics such as T2DM, plasma glucose, heart disease, hypertension, weight, height, body mass index, and waist/hip ratio of the participants were not collected and therefore we were not able to adjust the results accordingly. For example, an association of rs 1801278 with the risk of T2DM has been reported [29-31]. Therefore, future studies with adjustment of these parameters would be helpful. Second, the genotype frequencies of the gene variant were not in Hardy-Weinberg equilibrium. However, inasmuch as $10 \%$ of all genotype-phenotype association studies show deviation from Hardy-Weinberg equilibrium [40], the results of our trial cannot be considered abnormal. Nevertheless, we suggest future investigations with larger sample sizes.

To sum up, the findings from the present study indicate a significant association of mutant $\mathrm{A}$ allele and mutant homozygote AA genotype with the risk of AD after adjustment for sex and age. Further investigation is needed to assess the effects of rs 1801278 polymorphism on the severity of cognitive impairment to assess prognostic values.

\section{ACKNOWLEDGMENTS}

The authors have no acknowledgments to report.

\section{FUNDING}

Guilan University of Medical Sciences provided financial support for this study.

\section{CONFLICT OF INTEREST}

The authors declare no conflict of interest.

\section{REFERENCES}

[1] Olayinka O, Olayinka O, Alemu B, Akpinar-Elci M, Grossberg G (2019) Toxic environmental risk factors for Alzheimer's disease: A systematic review. Aging Med Healthcare 10, 4-17.

[2] Heidari F, Ansstas G, Ajamian F (2021) CD33 mRNA has elevated expression levels in the leukocytes of peripheral blood in patients with late-onset Alzheimer's disease. Gerontology. doi: 10.1159/000518820.

[3] Andalib S, Ghayeghran A, Moadabi Y, Asadi K, Mohammadpour M, Ghorbani-Shirkouhi S (2019) Association of 
diabetes mellitus type 2 and Alzheimer's disease. Caspian $J$ Health Res 4, 86-89.

[4] Prince MJ, Wimo A, Guerchet MM, Ali GC, Wu Y-T, Prina M (2015) World Alzheimer Report 2015. The Global Impact of Dementia: An analysis of prevalence, incidence, cost and trends. Alzheimer's Disease International, London.

[5] Ettcheto M, Cano A, Busquets O, Manzine PR, SánchezLópez E, Castro-Torres RD, Beas-Zarate C, Verdaguer E, García ML, Olloquequi J (2019) A metabolic perspective of late onset Alzheimer's disease. Pharmacol Res 145, 104255.

[6] Florez JC, Sjögren M, Burtt N, Orho-Melander M, Schayer S, Sun M, Almgren P, Lindblad U, Tuomi T, Gaudet D (2004) Association testing in 9,000 people fails to confirm the association of the insulin receptor substrate-1 G972R polymorphism with type 2 diabetes. Diabetes 53, 3313-3318.

[7] Huang X, Liu H, Li X, Guan L, Li J, Tellier LCAM, Yang H, Wang J, Zhang J (2018) Revealing Alzheimer's disease genes spectrum in the whole-genome by machine learning. BMC Neurol 18, 5.

[8] Moreno DJ, Ruiz S, Ríos Á, Lopera F, Ostos H, Via M, Bedoya G (2017) Association of GWAS top genes with lateonset Alzheimer's disease in Colombian population. Am J Alzheimers Dis Other Demen 32, 27-35.

[9] Jonsson T, Stefansson H, Steinberg S, Jonsdottir I, Jonsson PV, Snaedal J, Bjornsson S, Huttenlocher J, Levey AI, Lah JJ (2013) Variant of TREM2 associated with the risk of Alzheimer's disease. N Engl J Med 368, 107-116.

[10] Antúnez C, Boada M, González-Pérez A, Gayán J, RamírezLorca R, Marín J, Hernández I, Moreno-Rey C, Morón FJ, López-Arrieta J (2011) The membrane-spanning 4domains, subfamily A (MS4A) gene cluster contains a common variant associated with Alzheimer's disease. Genome Med 3, 1-8.

[11] Mehdizadeh E, Khalaj-Kondori M, Shaghaghi-Tarakdari Z, Sadigh-Eteghad S, Talebi M, Andalib S (2019) Association of MS4A6A, CD33, and TREM2 gene polymorphisms with the late-onset Alzheimer's disease. Bioimpacts 9, 219.

[12] Kuusisto J, Koivisto K, Mykkänen L, Helkala E-L, Vanhanen M, Hänninen $\mathrm{T}$, Kervinen K, Kesäniemi YA, Riekkinen PJ, Laakso M (1997) Association between features of the insulin resistance syndrome and Alzheimer's disease independently of apolipoprotein E4 phenotype: Cross sectional population based study. BMJ 315, 1045-1049.

[13] Biessels GJ, Staekenborg S, Brunner E, Brayne C, Scheltens P (2006) Risk of dementia in diabetes mellitus: A systematic review. Lancet Neurol 5, 64-74.

[14] Esteghamati A, Etemad K, Koohpayehzadeh J, Abbasi M, Meysamie A, Noshad S, Asgari F, Mousavizadeh M, Rafei A, Khajeh E (2014) Trends in the prevalence of diabetes and impaired fasting glucose in association with obesity in Iran: 2005-2011. Diabetes Res Clin Pract 103, 319-327.

[15] Javanbakht M, Mashayekhi A, Baradaran HR, Haghdoost A, Afshin A (2015) Projection of diabetes population size and associated economic burden through 2030 in Iran: Evidence from micro-simulation Markov model and Bayesian metaanalysis. PloS One 10, e 0132505.

[16] Hasandokht T, Joukar F, Marroufizadeh S, Sibevey S, Naghipour M, Mansour-Ghanaei F (2020) Detection of high risk people for diabetes by American Diabetes Association Risk Score in PERSIAN Guilan Cohort Study. Research Square, https://doi.org/10.21203/rs.3.rs-111051/v1.
[17] Ferrario CR, Reagan LP (2018) Insulin-mediated synaptic plasticity in the CNS: Anatomical, functional and temporal contexts. Neuropharmacology 136, 182-191.

[18] Chiu S-L, Cline HT (2010) Insulin receptor signaling in the development of neuronal structure and function. Neural Dev $\mathbf{5}, 7$.

[19] Park C (2001) Cognitive effects of insulin in the central nervous system. Neurosci Biobehav Rev 25, 311-323.

[20] Arnold SE, Arvanitakis Z, Macauley-Rambach SL, Koenig AM, Wang H-Y, Ahima RS, Craft S, Gandy S, Buettner C, Stoeckel LE (2018) Brain insulin resistance in type 2 diabetes and Alzheimer disease: Concepts and conundrums. Nat Rev Neurol 14, 168.

[21] McNay EC, Fries TM, Gold PE (2000) Decreases in rat extracellular hippocampal glucose concentration associated with cognitive demand during a spatial task. Proc Natl Acad Sci U S A 97, 2881-2885.

[22] McNay EC, Gold PE (2002) Food for thought: Fluctuations in brain extracellular glucose provide insight into the mechanisms of memory modulation. Behav Cogn Neurosci Rev 1, 264-280.

[23] McNay EC, Cotero VE (2010) Mini-review: Impact of recurrent hypoglycemia on cognitive and brain function. Physiol Behav 100, 234-238.

[24] Apelt J, Mehlhorn G, Schliebs R (1999) Insulin-sensitive GLUT4 glucose transporters are colocalized with GLUT3expressing cells and demonstrate a chemically distinct neuron-specific localization in rat brain. J Neurosci Res $\mathbf{5 7}$, 693-705.

[25] Mayeda ER (2019) Invited commentary: Examining sex/gender differences in risk of Alzheimer disease and related dementias - challenges and future directions. Am J Epidemiol 188, 1224-1227.

[26] Blázquez E, Velázquez E, Hurtado-Carneiro V, RuizAlbusac JM (2014) Insulin in the brain: Its pathophysiological implications for States related with central insulin resistance, type 2 diabetes and Alzheimer's disease. Front Endocrinol 5, 161.

[27] Sesti G, Federici M, Hribal ML, Lauro D, Sbraccia P, Lauro $\mathrm{R}$ (2001) Defects of the insulin receptor substrate (IRS) system in human metabolic disorders. FASEB J 15, 2099-2111.

[28] Wang W, Yang L, Tan L, Wu X, Jiang B, Shen X (2014) Arg972 insulin receptor substrate-1 polymorphism and risk and severity of Alzheimer's disease. J Clin Neurosci 21, 1233-1237.

[29] Albegali AA, Shahzad M, Mahmood S, Ullah MI (2019) Genetic association of insulin receptor substrate-1 (IRS-1, rs1801278) gene with insulin resistant of type 2 diabetes mellitus in a Pakistani population. Mol Biol Rep 46, 60656070.

[30] Alharbi KK, Khan IA, Munshi A, Alharbi FK, Al-Sheikh Y, Alnbaheen MS (2014) Association of the genetic variants of insulin receptor substrate 1 (IRS-1) with type 2 diabetes mellitus in a Saudi population. Endocrine 47, 472-477.

[31] Li Q, Qiao Y, Wang C, Zhang G, Zhang X, Xu L (2016) Associations between two single-nucleotide polymorphisms (rs1801278 and rs2943641) of insulin receptor substrate 1 gene and Type 2 diabetes susceptibility: A metaanalysis. Endocrine 51, 52-62.

[32] Giedraitis V, Kilander L, Degerman-Gunnarsson M, Sundelöf J, Axelsson T, Syvänen A-C, Lannfelt L, Glaser A (2009) Genetic analysis of Alzheimer's disease in the Uppsala Longitudinal Study of Adult Men. Dement Geriatr Cogn Disord 27, 59-68. 
[33] Hamilton G, Proitsi P, Jehu L, Morgan A, Williams J, O'Donovan MC, Owen MJ, Powell JF, Lovestone S (2007) Candidate gene association study of insulin signaling genes and Alzheimer's disease: Evidence for SOS2, PCK1, and PPAR $\gamma$ as susceptibility loci. Am J Med Genet B Neuropsychiatr Genet 144, 508-516.

[34] Coon KD, Myers AJ, Craig DW, Webster JA, Pearson JV, Lince DH, Zismann VL, Beach TG, Leung D, Bryden L (2007) A high-density whole-genome association study reveals that APOE is the major susceptibility gene for sporadic late-onset Alzheimer's disease. J Clin Psychiatry 68, 613-618.

[35] Li H, Wetten S, Li L, Jean PLS, Upmanyu R, Surh L, Hosford D, Barnes MR, Briley JD, Borrie M (2008) Candidate single-nucleotide polymorphisms from a genomewide association study of Alzheimer disease. Arch Neurol 65, 45-53.

[36] McKhann GM, Knopman DS, Chertkow H, Hyman BT, Jack Jr CR, Kawas CH, Klunk WE, Koroshetz WJ, Manly JJ, Mayeux R (2011) The diagnosis of dementia due to Alzheimer's disease: Recommendations from the National
Institute on Aging-Alzheimer's Association workgroups on diagnostic guidelines for Alzheimer's disease. Alzheimers Dement 7, 263-269.

[37] Federici M, Petrone A, Porzio O, Bizzarri C, Lauro D, D'Alfonso R, Patera I, Cappa M, Nisticò L, Baroni M (2003) The Gly972 $\longrightarrow$ Arg IRS-1 variant is associated with type 1 diabetes in continental Italy. Diabetes 52, 887-890.

[38] Reiman EM, Webster JA, Myers AJ, Hardy J, Dunckley T, Zismann VL, Joshipura KD, Pearson JV, Hu-Lince D, Huentelman MJ (2007) GAB2 alleles modify Alzheimer's risk in APOE $\varepsilon 4$ carriers. Neuron 54, 713-720.

[39] Figgins JA, Minster RL, Demirci FY, DeKosky ST, Kamboh MI (2009) Association studies of 22 candidate SNPs with late-onset Alzheimer's disease. Am J Med Genet B Neuropsychiatr Genet 150, 520-526.

[40] Trikalinos TA, Salanti G, Khoury MJ, Ioannidis JP (2006) Impact of violations and deviations in Hardy-Weinberg equilibrium on postulated gene-disease associations. Am J Epidemiol 163, 300-309. 